\title{
A Case Study: Vipadikahara Grita Taila as a Remedy for Vipadika Skin Disease
}

\author{
HGSP Hewageegana ${ }^{* *}$ and LDAM Arawwawala² \\ ${ }^{1}$ Institute of Indigenous Medicine, University of Colombo, Rajagiriya, Sri Lanka \\ ${ }^{2}$ Industrial Technology Institute, Research \& Development Complex, Thalahena, Malabe, Sri Lanka
}

${ }^{*}$ Corresponding author: HGSP Hewageegana, Institute of Indigenous Medicine, University of Colombo, Rajagiriya, Sri Lanka, E-mail: sujathahgsp@yahoo.com

Received: 29 Nov, 2017 | Accepted: 26 Dec, 2017 | Published: 04 Jan, 2018

Citation: HGSP Hewageegana, (2018) A Case Study: Vipadikahara Grita Taila as a Remedy for Vipadika Skin Disease. J Network Med Target Ther 1(1): dx.doi.org/10.16966/2577-1906.107

Copyright: (C) 2018 HGSP Hewageegana, et al. This is an openaccess article distributed under the terms of the Creative Commons Attribution License, which permits unrestricted use, distribution, and reproduction in any medium, provided the original author and source are credited.

\begin{abstract}
Vipadikahara grita taila is a specific medicated oil, used externally to treat the "Vipadika" skin disease. According to Ayurveda, fissures and cracks in the feet and hands with severe pain are the symptoms of Vipadika. The aim of the present study was to evaluate the effectiveness of Vipadikahara grita taila on Vipadika skin disease. Herewith, reporting a case of 58-year-old female house wife who was presented for the treatment of bilateral large cracks and fissures in feet since 1999. According to clinical presentation, this case demonstrated Vipadika skin disease (a type of Ksudra kushta according to Ayurveda aspect). Standardized Vipadikahara grita taila was applied over the affected area twice a day: morning and evening in dried feet after washing with Luke warm water for 6 weeks duration. The lesions were progressively cured during the treatment period and gradually the skin of the feet became almost normal. The present study has proven that Vipadikahara grita taila can be used externally as an effective medicated oil to manage Vipadika skin disease.
\end{abstract}

Keywords: Vipadikahara Grita Taila; Medicated Oil; Vipadika Skin Disease

\section{Introduction}

Vipadika skin disease has symptoms of fissures and cracks in the feet and hands with severe pain. Vipadikahara grita taila is a medicated oil which was mentioned in Caraka Samhita in Kushta chikitsa [1] as a treatment for five types of skin diseases such as, Vipadika, Carma kushta, Eka kushta, Kitibha and Alaska. Medicinal plants and other ingredients of the Vipadikahara grita taila are Leptadenia reticulate (Retz) Wight (family: Asclepiadaceae), Rubia cordifolia Linn Syst (family: Rubiaceae), Berberis aristata DC. Syst., (family: Berberidaceae), Mallotus phillipinensis (Lam.) Muell. Arg. (family: Euphorbiaceae), Cow's milk, Bee's wax, Resin of Shorea robusta Roth (family: Dipterocarpeae), Sesame oil (family: Pedaliaceae) and cow's ghee [2]. Vipadikahara grita taila was prepared at the Pharmacy, Institute of Indigenous Medicine, University of Colombo, and Rajagiriya, Sri Lanka according to the oil preparing method described in Ayurveda pharmacopoeia: In brief, dirt free plant materials were mixed with water and the mixture was heated using mild flame until the volume of water reduced to one fourth of the original volume. Then cow's milk and Sesame oil was added and allowed to reduce the volume further. After that, the mixture was filtered through a muslin cloth and added Bee's wax and resin of Shorea robusta when the content was in hot.

Furthermore, quality assessment of Vipadikahara grita taila was carried out according to standard protocols $[3,4]$. In the present study, an attempt was taken to investigate the efficacy of Vipadikahara grita taila on Vipadika skin disease.

A female house wife (age: 58 years) was brought by her relatives to Outpatient Department (Kayachikitsa clinic) at Ayurveda Teaching Hospital, Borella, Sri Lanka in the year 2014. She had complaints of bilateral large cracks and fissures in feet with pain, burning sensation, roughness from 05 years. Initially, it was started from the site of the heels and gradually spread to the other part of the foot. Even though there were exacerbations and remissions during disease period, she felt severe pain throughout the day and night. When the cracks were particularly bad, she felt fever and walking difficulty. According to her experience, when she consumed foods such as tomato, salmon, toona fish and vinegar added curries, fissures and cracks and pain got worse. Her vitals were stable with Height - $147 \mathrm{~cm}$, Weight - $58 \mathrm{~kg}$, B.P. 120/80 mm of $\mathrm{Hg}$. Allopathic medicine provided some relief at the beginning and it was not permanent. Therefore, she has sought Ayurveda treatment. Other than this skin problem, the patient has reported that she was in good health. According to symptoms, this case demonstrated a classical presentation of Vipadika skin disease. During the examination, it was revealed that patient was free from the symptoms of diabetes mellitus, hypertension, and chronic lung disease, malignancy, sensitivity reactions to 
the medicated oils and Vipadika with secondary infections. Further, the patient did not consume any topical steroid/s for a longer period. Furthermore, there was no family history of such skin disease or any other type of skin diseases.

\section{Methodology}

The present study was conducted at Ayurveda Teaching Hospital, Borella, Sri Lanka in the year 2014. Ethical approval was obtained from an ethical review committee of Institute of Indigenous Medicine, the University of Colombo, Sri Lanka (Re. No: 12/06). Consent of the patient was taken before starting the treatment. The patient was advised to apply the oil over the affected area twice a day: morning and evening in dried feet after washing with Luke warm water (duration was 6 weeks and volume of the oil was $60 \mathrm{~mL}$ per week). The patient was reviewed once a week at the clinic in Ayurveda Teaching Hospital. The patient was advised not to apply any other remedy on the skin lesion during the study period and also not to apply the test drug on the day of assessment. The follow-up period was 03 months.

The evaluation was based on the reduction of the cardinal symptoms and healing of wounds by measuring the length, width, depth, and number of ulcers. Assessments of cardinal symptoms were carried out by using a Numeric Rating Scale as given below.

\section{Under symptom Itching}

\begin{tabular}{|l|c|}
\hline No itching & 0 \\
\hline Mild itching (only aware of itching when relaxing) & 1 \\
\hline Moderate (sometime disturb the sleep and day time activity) & 2 \\
\hline Severe (constant itching, frequent sleep disturbance) & 3 \\
\hline
\end{tabular}

\section{Under symptom Roughness and Dryness}

\begin{tabular}{|l|l|}
\hline Insignificant dryness at the foot/palms & 0 \\
\hline Roughness is present when touching & 1 \\
\hline Excessive roughness presents and leading to itching & 2 \\
\hline Excessive roughness presents and leading to slight cracks & 3 \\
\hline Roughness leading to cracks and fissures & 4 \\
\hline
\end{tabular}

\section{Under symptom Cracks}

\begin{tabular}{|l|l|}
\hline No cracking & 0 \\
\hline Length of the crack is less than $1 \mathrm{~cm}$ & 1 \\
\hline Length of the crack is between $1.1 \mathrm{~cm}$ and $1.5 \mathrm{~cm}$ & 2 \\
\hline Length of the crack between $1.6 \mathrm{~cm}$ and $2 \mathrm{~cm}$ & 3 \\
\hline Length of the crack is between $2.1 \mathrm{~cm}$ and $3 \mathrm{~cm}$ & 4 \\
\hline Length of the crack is more than $3 \mathrm{~cm}$ & 5 \\
\hline
\end{tabular}

\section{Under symptom Pain}

\begin{tabular}{|l|l|}
\hline No pain & 0 \\
\hline Mild pain of easily bearable nature, comes occasionally & 1 \\
\hline Moderate pain, but no difficulty & 2 \\
\hline Appears frequently and requires some measures for relief & 3 \\
\hline Pain requires medication and may remain throughout the day & 4 \\
\hline $\begin{array}{l}\text { More difficulty: pain is severe, disturbing sleep and requires } \\
\text { analgesics }\end{array}$ & 5 \\
\hline
\end{tabular}

Under symptom Burning Sensation at the affected site

\begin{tabular}{|l|c|}
\hline No burning at the affected site & 0 \\
\hline $\begin{array}{l}\text { Mild burning at the affected site but bearable nature comes } \\
\text { occasionally }\end{array}$ & 1 \\
\hline Moderate burning at the affected site, but no difficulty & 2 \\
\hline $\begin{array}{l}\text { Burning present all over the day: requires some measures for } \\
\text { relief (water) }\end{array}$ & 3 \\
\hline $\begin{array}{l}\text { Requires some medical applications but may remain throughout } \\
\text { the day }\end{array}$ & 4 \\
\hline More difficulty and burning is severe, disturbing sleep & 5 \\
\hline
\end{tabular}

Overall results related to observations for the patient (final assessment) was done as follows:

1. Complete remission: $100 \%$ relief in the signs and symptoms.

2. Marked improvement: more than $76 \%$ relief in the signs and symptoms.

3. Moderate Improved: $51-75 \%$ relief in the signs and symptoms.

4. Improved: $26-50 \%$ relief in the signs and symptoms.

5. Unchanged: Below $25 \%$ relief in the signs and symptoms

After completing the treatment, the patient was kept for further three-month under the supervision as a follow-up study.

\section{Statistical Analysis}

Assessment criteria were based on the effect of the treatment. Thus, evaluation was based on the reduction of the cardinal symptoms. Physical findings were evaluated before treatment, during the treatment, and after treatment and calculated separately and compared statistically using Mann Whitney $\mathrm{u}$ test. The results were expressed as mean \pm SEM. Finding of $\mathrm{P}<0.05$ were considered to indicate statistical significance.

\section{Results and Discussion}

The lesions were progressively cured during the treatment period and gradually the skin of the feet became almost normal (Figure 1). The length, width and the depth of the lesion were reduced in $89.8 \%, 90.0 \%$, and $90.3 \%$ respectively. In addition, itching, roughness, fissures, pain, oedema, burning sensation, the eruption of papules, dark shade and redness in the affected site were also considerably reduced with the treatment. Wound healing properties of this medicated oil would directly help to cure these fissures. Interestingly, this medicated oil also has promising antibacterial property in addition to the wound healing property [5].

Further, after applying oily preparations, it should remain on skin for sometimes [6]. The selection of an optimum base for the topical preparation is extremely essential in Ayurveda as it provides easy access to the active principles of the drugs up to the deepest stratum of the skin. Absorption of substances through the skin depends duration of contact and on the solubility of medication. In this study, Vipadikahara grita taila was applied morning and evening after cleansing the wounds. Therefore, it remains several hours in the skin. 


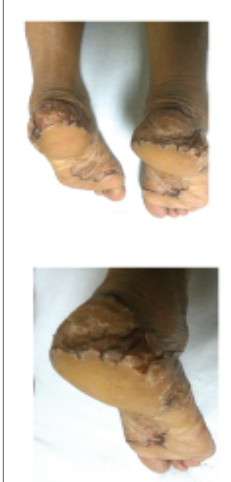

Before treatment
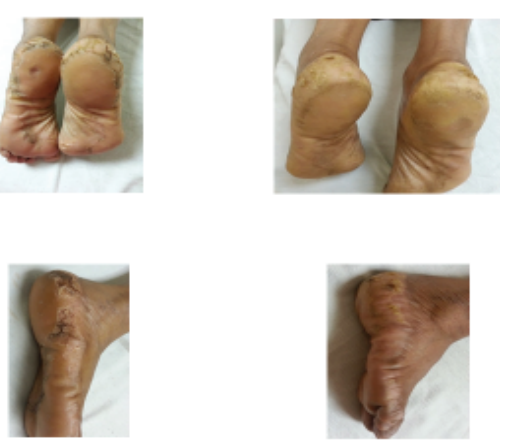

After 3 weeks

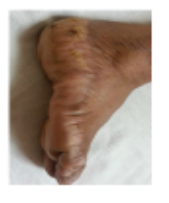

After 6 weeks

Figure 1: Vipadika skin lesion before treatment, after 3 weeks treatment and after 6 weeks treatment with Vipadikahara grita taila

Vipadikahara grita taila is rich in phenolic compounds, tannins, saponins, steroid glycosides and coumarin. Therefore, it possesses high medicinal value though it contains less number of medicinal plants [4] and helps to heal wounds in many ways such as analgesics, anti-inflammatory, and antimicrobial activities. Since Vipadikahara grita taila is rich in phenolic compounds, which facilitate the wound healing.

\section{Conclusion}

Present case study had proven that Vipadikahara ghrita taila can be used externally as an effective medicated oil to manage the Vipadika skin lesion.

\section{Acknowledgement}

National Centre for Advanced Studies for Humanities and Social Sciences, Ward Place, Colombo 7, Sri Lanka is acknowledged for providing financial assistance.

\section{References}

1. Sengupta S, Sengupta SB (1991) Caraka samhita (Vol IIINidanasthana, Cikitsasthana). Chaukhambha Orientalia, Varanasi.

2. Senagupta N (1855) Caraka Samhita (Vol III- Cikitsasthana). Sri Rangalalaminnena press, India.

3. Indian Standard Methods of Sampling and Test for Oils and Fats, Part 1 (1976) Sampling, Physical and Chemical Tests, Bureau of Indian Standards.

4. Hewageegana HGSP, Arawwawala LADM, Fernando PIPK, Dhammarathana I, Ariyawansa HAS, et al (2013) Standardization of Vipadikahara grita taila: an Ayurvedic medicated oil for common skin lesions. Uni J of Ayu and Herb Med 1: 48-51.

5. Hewageegana HGSP, Arawwawala LADM, Kottahachchi J, Athukorala GIDDAD, Weerasekera MM, et al. (2013) Standardization and Evaluation of the Antibacterial activity of Vipadikahara grita taila, International Conference on Ayurveda Unani Siddha and Traditional Medicine p.34.

6. Absorption (skin). 